\title{
Chapter 9 \\ River Connectivity, Habitat Fragmentation and Related Restoration Measures
}

\author{
Carina Seliger and Bernhard Zeiringer
}

\subsection{The Importance of Connectivity in Riverine Ecology}

For a long time, connectivity conservation focused on interactions and exchanges between terrestrial and, in most cases, homogenous habitat patches. Thereby, rivers have all too often been considered as two-dimensional elements of terrestrial landscapes neglecting their own internal structure and heterogeneity (Wiens 2002). It was therefore not until the early 1980s that the term "river corridors" started to appear in scientific literature only to be then gradually replaced by the term "connectivity" (Amoros and Roux 1988; Pringle 2006) for describing the spatial connections within river systems (Ward 1997; Wiens 2002).

Although knowledge and approaches from terrestrial assessments can also be transferred to aquatic ecosystems, rivers exhibit certain characteristics, which should grant them a special position in connectivity conservation:

1. Riverine systems are characterized by their inherent water-mediated connectivity wherein the river itself represents both habitat and migration corridor (Ward 1989; Wiens 2002). As a consequence, two sites with a low Euclidean distance may indeed show a stream distance of several hundreds of kilometres (Labonne et al. 2008).

2. Connectivity acts on one temporal and three spatial dimensions: longitudinally from headwaters to confluences and the sea, laterally from the main channel to floodplains and vertically from the river towards the hyporheic interstitial and the groundwater (Ward 1989; Jungwirth et al. 2003). The importance of each dimension changes along the river course (Vannote et al. 1980; Ward and Stanford 1995b) and leads to the development of different river concepts (see below).

C. Seliger $(\bowtie) \cdot$ B. Zeiringer

Institute of Hydrobiology and Aquatic Ecosystem Management, University of Natural

Resources and Life Sciences, Vienna, Austria

e-mail: carina.seliger@boku.ac.at; bernhard.zeiringer@boku.ac.at 
3. Hydrologic connectivity supports the passive downstream transport of matter and energy (Ward and Stanford 1995a; Pringle 2006) but enables a multidimensional dispersal of organisms (Ward and Stanford 1995a; Branco et al. 2014).

4. While terrestrial connectivity often focuses on interactions of homogenous patches, the connection of different habitats is equally or, in aquatic ecology, maybe even more important, since certain species and life stages require diverse habitat patches to complete their life cycle (Jungwirth et al. 2003).

The longitudinal alteration of physical parameters in the downstream direction does not only affect the four dimensionality of rivers but also induces the development of distinct life strategies of organisms living in the river (see Fig. 9.1). Vannote et al. (1980) developed the "River Continuum Concept" (RCC) to highlight the longitudinal, biocoenotic change related to hydro-morphological conditions on a functional basis (i.e. expressed as production/respiration ratio). While the RCC focused on the downstream succession of feeding types, it was criticized for insufficiently considering the lateral and vertical dimensions. Furthermore, due to its limited applicability to anthropogenically disturbed systems, it was followed by the "extended serial discontinuity concept" (ESDC). Developed by Ward and Stanford $(1983,1995 b)$ to describe the longitudinal variation of the four dimensions, the ESDC also allowed the incorporation of anthropogenic alterations. In particular, it considers barriers as well as thermal and flow alterations (e.g. induced by impoundments or water abstractions), which also interrupt the river continuum (Ward and Stanford 1983; Branco et al. 2014) (see Sect. 9.2).

Since both habitats and populations are potentially connected by said four dimensionality (Ward 1989, 1997), ecologists usually differentiate between ecological and landscape/riverscape connectivity. The former deals with the fundamental concept of metapopulation ecology and discusses the impacts of limited genetic exchange between populations (Moilanen and Hanski 2006). Riverscape connectivity, on the other hand, can be further divided into two kinds of connectivity: structural-to characterize relationships between habitat patches (i.e. quantity, location and potential corridors connecting them) (Keitt et al. 1997; Tischendorf and Fahrig 2000; Antongiovanni and Metzger 2005; Segurado et al. 2013) - and functional connectivity, to describe the complex relationships and biological response of individuals or populations to the landscape structure (Tischendorf and Fahrig 2000), which depends on the ecology of the species of concern (e.g. preferences, swimming abilities, requirements) (Bowne et al. 2006).

Aquatic organisms, and especially fish as vagile organisms, evolved in relation to habitat distribution and adapted their life history patterns in response to their connectivity over space and time (Ward 1989; Jungwirth et al. 2000; Schmutz and Mielach 2013). Consequently, all fish species perform targeted "habitat shifts" to exploit a diverse array of habitats (Schmutz et al. 1997; Jungwirth 1998; Mader et al. 1998; Northcote 1998) and to optimize their production and use of resources in response to changing requirements (e.g. for distribution, growth, reproduction, shelter and protection from predators) or changing habitat patches (e.g. due to floods, climate change, etc.) (Northcote 1978, 1998; Lancaster 2000; Wiens 2002). As the 


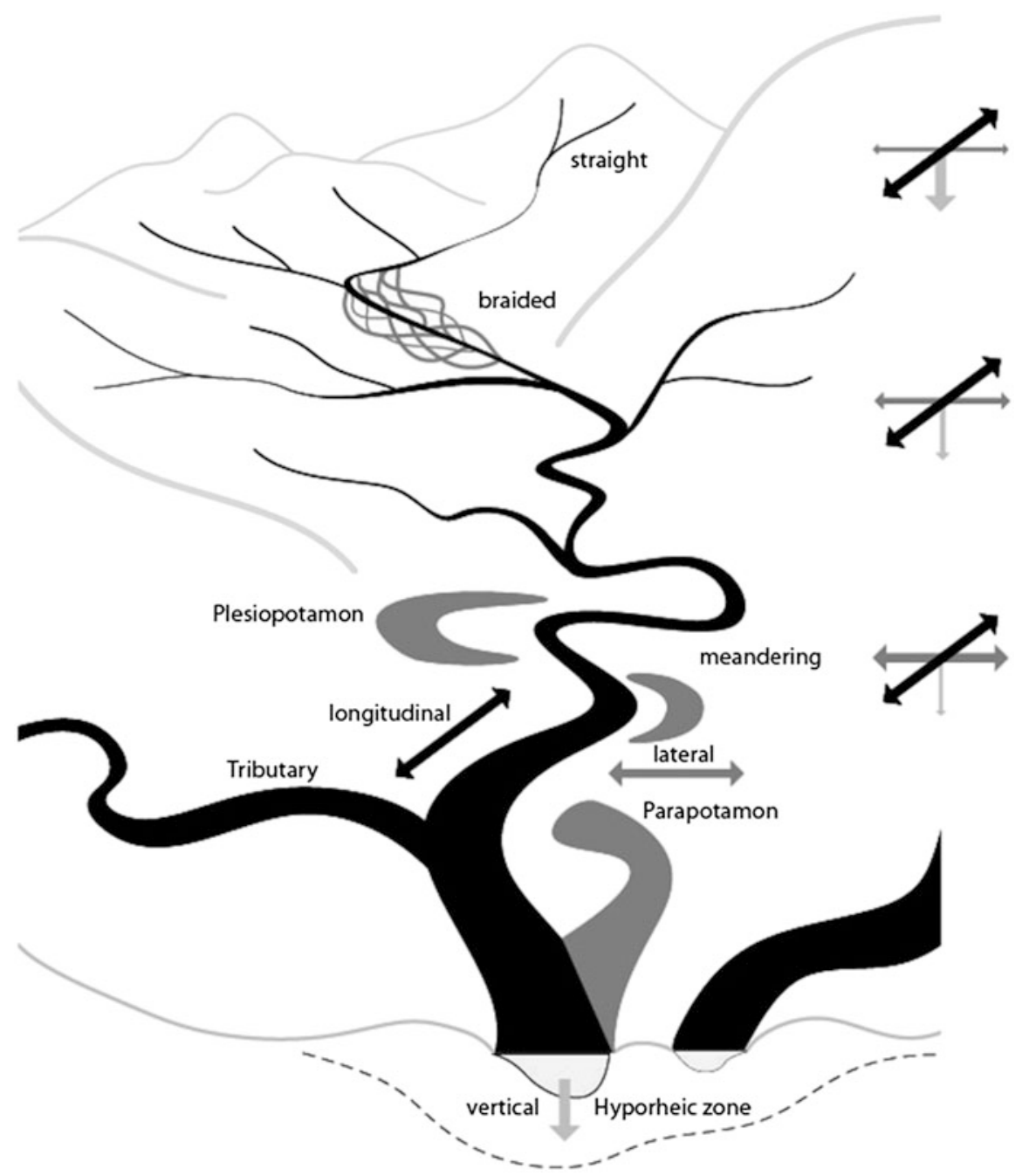

Fig. 9.1 Longitudinal succession of the three spatial dimensions and their importance for aquatic organisms and fish in particular (based on Jungwirth et al. 2000; Amoros et al. 1987)

integrity of fish populations relies to a high degree on the availability and accessibility of spatially separated habitat patches within the river network, fish are good indicators for continuity and connectivity conditions in riverine ecosystems (Jungwirth et al. 2003).

Fish migrations are usually induced by several complex and often interacting factors (Pavlov 1989; Colgan 1993; Lucas and Baras 2001). Examples are water temperature, season, light, discharge, water quality but also internal factors as imprinting and homing effect (Lucas and Baras 2001). While spawning migrations mostly occur towards headwaters, tributaries or floodplains, downstream migrations 
are usually related to spreading, drift, accessing autumn/winter habitats and return migrations from spawning habitats (Jungwirth et al. 2003).

Fish species can be classified according to their migratory guild as diadromous (inhabiting both seawater and freshwater habitats during certain life stages) and potamodromous (only in freshwater systems). Potamodromous species are characterized by migrations related to (1) spawning, (2) passive drift of larvae and juveniles, (3) age-related habitat changes, (4) flood migrations/catastrophic drift, (5) seasonal habitat shifts (e.g. winter habitats), (6) migrations regarding feeding/ nutrition and (7) dispersal migrations. Depending on the migratory distance, long-, medium- and short-distance migrations are distinguished (i.e. $>300,30-300$ or $<30 \mathrm{~km}$ in one direction per year) (Waidbacher and Haidvogl 1998; Jungwirth et al. 2003).

Although many species spawn in inundated floodplains and rely on intact lateral connectivity, this chapter addresses exclusively longitudinal connectivity, leaving lateral connectivity to be discussed in other chapters (e.g. Chaps. 3 and 6).

\subsection{River Fragmentation}

Rivers belong to the most diverse ecosystems on earth (Bosshard 2015) but are highly threatened by habitat fragmentation (Dynesius and Nilsson 1994; Nilsson et al. 2005). On a global scale, there are currently more than 58,400 large dams (i.e. $>15 \mathrm{~m}$ in height) which mainly serve the purpose of irrigation, hydropower production, water supply and flood control (ICOLD 2016). These dams fragment more than $60 \%$ of all large rivers (i.e. $>1000 \mathrm{~km}$ in length) with even higher fragmentation rates in Europe where only $28 \%$ of large rivers remain free flowing (WWF 2006).

Due to limited migration opportunities in stream networks, disconnections are particularly damaging, making it more difficult or even impossible for fish to avoid barriers (Fagan 2002; Fullerton et al. 2010). Therefore, the dramatic loss in global aquatic biodiversity is not surprising (Pringle et al. 2000; Rosenberg et al. 2000). With $37 \%$ of Europe's freshwater fishes threatened and another $4 \%$ near-threatened with extinction, they show one of the highest threat levels of any major taxonomic group (Freyhof and Brooks 2011). As it is assumed that 10,000-20,000 freshwater species are already extinct or at risk of extinction (Vörösmarty et al. 2010), the current rates are more than 1000 times the normal background rate (Master 1990). This may explain the steep decline in abundance since the mid-1980s (Latham et al. 2008) for migratory fish species, which are particularly susceptible to fragmentation (Lucas and Baras 2001; Pringle 2006; Ovidio and Philippart 2008). Examples include endangered medium-distance migrants (e.g. Acipenser ruthenus, Hucho hucho) and large-distance migratory species (e.g. Acipenser stellatus, Huso huso) which became extinct in the upper Danube catchment as a consequence of the closure of the Iron Gate dams (Spindler et al. 1997; Jungwirth et al. 2003). 


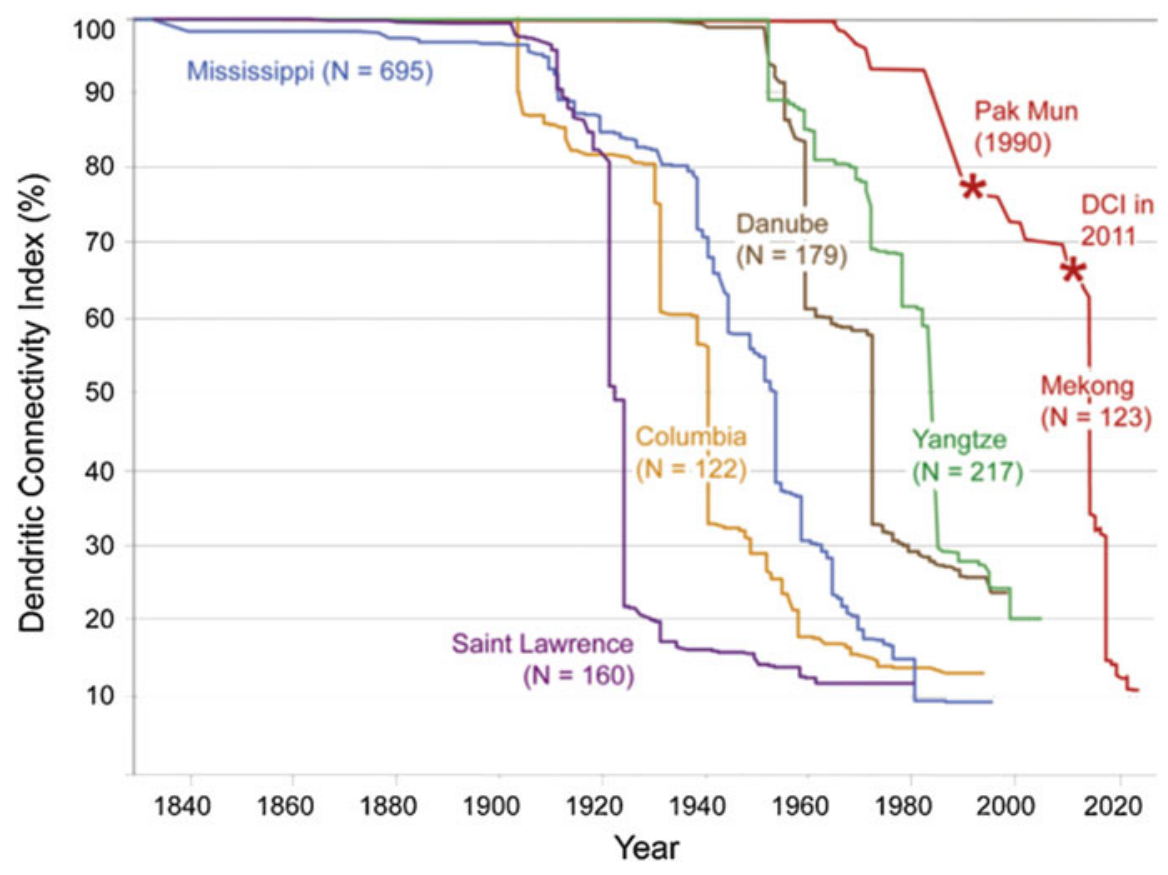

Fig. 9.2 Historic development of the dendritic connectivity index (DCI; Cote et al. 2009) for selected large river basins (Grill et al. 2014) (reprinted from Ecological Indicators, 45, Grill G., Dallaire C.O., Chouinard E.F., Sindorf N., Lehner B., Development of new indicators to evaluate river fragmentation and flow regulation at large scales: A case study for the Mekong River Basin, 148-159, (C) 2014, with permission from Elsevier Inc. All rights reserved)

The construction of weirs represents the most obvious way to fragment riverine habitats. However, dams may also be associated with other hydro-morphological changes, which then alter the spatial and temporal patch composition and, consequently, connectivity patterns (Wiens 2002). In this context, residual flow sections and impoundments may not only alter habitats but can also contribute to habitat fragmentations by preventing fish migrations through sections with limited water depths and flow velocities (see Chaps. 4 and 6).

The intensity of fragmentation is often expressed by the number of dams within a catchment or per river-km and the mean or maximum length between two barriers (Nilsson et al. 2005; Grill et al. 2014). However, these statements do not allow causal conclusions on the distribution and, consequently, the ecological impact of barriers.

The dendritic connectivity index (DCI; Cote et al. 2009) represents an easy and elegant way to describe catchment fragmentation (see Fig. 9.2). For binary passability ratings, the DCI is calculated as shown below, where $\mathrm{n}$ is the number of fragments, $l_{i}$ is the river length of the fragment $i$ and $L$ is the total length of the entire river network. 


$$
D C I=\sum_{i=1}^{n} \frac{l_{i}^{2}}{L^{2}} * 100
$$

As fragmentation began in the early twentieth century, several large rivers experienced rapid reductions in their connectivity, and the same is expected for many other rivers (e.g. the Mekong) if current hydropower plans are implemented (Grill et al. 2014).

One key disadvantage of the DCI is that it considers the entire river network as equally important and thereby neglects the fact that some sections are more vulnerable to fragmentation than others (see also Sect. 9.3.1). While barriers close to the river mouth disconnect the entire catchment upstream, dams in headwaters make only small proportions inaccessible. To take this into account, Grill et al. (2014) extended the DCI by ecologically relevant weighting factors (e.g. river volume or river classes). Furthermore, to reflect the importance of a segment for migratory fish, the "River Migration Connectivity Index" (RMCI) incorporates the proportion of migratory species potentially visiting a river fragment (Grill et al. 2014).

\subsection{Restoration of Longitudinal Continuity}

With habitat fragmentation progressing worldwide, ecological research put much effort into conservation measures for maintaining and restoring connectivity of riverine habitats (e.g. Mesa and Magie 2009; Kemp and O'Hanley 2010; O'Hanley 2011; Segurado et al. 2013; Branco et al. 2014). The importance of continuity restoration is reflected in several international and national directives and frameworks (European Commission 1992, 2000; Schmutz and Mielach 2013; ICPDR 2015) and consequently is of high importance in aquatic habitat restoration (Branco et al. 2014).

As it is the case for all environmental impacts, it is recommended to make use of the full management action hierarchy, starting with avoidance, minimization, mitigation and, only if unavoidable, compensation. Ideally, these steps should be considered on a large scale (e.g. catchments or sub-catchments) and support the local decision process. While most new dams already incorporate solutions for sustaining fish migrations, fish pass facilities of existing dams, if present at all, are all too often inoperable, since subsequent retrofitting is both expensive and, due to the large number of impassable dams, time consuming. Therefore, large-scale assessments can also help to identify existing barriers with high priority for continuity restoration. We first examine such large-scale assessments in detail (Sect. 9.3.1) and then discuss state-of-the art solutions for impact avoidance and restoration of individual barriers (Sect. 9.3.2). 


\subsubsection{Large-Scale Concepts}

As proposed by Hartmann et al. (2013), hydropower planning should take place on the system scale and consider multiple parameters (Seliger et al. 2016). The selection of criteria depends on the respective conservation goal (e.g. conservation of overall connectivity or of species-specific migration routes) and can include both qualitative (e.g. habitat quality) or quantitative data (e.g. distance to the next barrier).

Opperman et al. (2015) performed multiple dam building scenarios for three case studies and compared them on the basis of hydropower capacity and impacts on connectivity (defined as the longest connected network in the catchment). They showed that the impacts on connectivity varied considerably between scenarios with the same energy output and that a certain share of the hydropower capacity (or a certain number of barriers) can usually be realized with insignificant connectivity declines. Consequently, large-scale assessments represent one possible approach to significantly reduce the overall impact (Opperman et al. 2015; Seliger et al. 2016; see also Chap. 23).

Also the International Commission for the Protection of the Danube River (ICPDR) developed a two-level approach for guiding sustainable hydropower development in the Danube catchment (ICPDR 2013). Site-specific mitigation measures can be planned after identifying locations with favourable hydropower potential and ecological criteria (ICPDR 2013).

As efficient as large-scale concepts can be for decision-making on new barriers, they can just as well support the planning process for restoring existing dams. Continuity restoration for all existing obstacles in a river might not be feasible or expedient. Due to limited resources (e.g. time, money), it might be worthwhile to identify those barriers where continuity restoration yields the best ecological benefit. This is, of course, only the case if suitable habitats are made accessible. Consequently, the inclusion of habitat quality parameters is highly recommended.

Several examples for the prioritization of barriers for continuity restoration already exist (e.g. O'Hanley and Tomberlin 2005; Mesa and Magie 2009; O'Hanley 2011; Segurado et al. 2013). Also transnational implementations are applicable, as shown by the prioritization index applied for the Danube catchment (ICPDR 2015) assigning decreasing importance from the Danube to the tributaries and including protected areas, length of the reconnected habitat and presence of other hydromorphological pressures. The prioritization index of the ICPDR and many others are based on simple cost-benefit analysis, including a set of assessment criteria to identify barriers of importance. While such scoring-and-ranking systems (e.g. Karle 2005) are easy to apply and comprehend, they assess each barrier independently. On the other hand, detailed GIS analyses (performing "what if"-type assessments) (Dumont et al. 2005; Gough et al. 2012) and optimization models (Kuby et al. 2005; O'Hanley and Tomberlin 2005) which can incorporate cumulative effects remain reserved for specialists (Kemp and O'Hanley 2010).

Although large-scale concepts represent suitable tools for both protecting and restoring aquatic ecosystems, they are rarely applied, and decisions are all too often 
made on a case-by-case basis. Furthermore, while prioritization concepts provide guidance for efficient continuity restoration, on the long run, all barriers in natural fish habitats should be made passable in both ways.

\subsubsection{Fish Migration Aids}

Once the barriers for continuity restoration are known, suitable mitigation measures have to be investigated. Since up- and downstream migrations require different settings, they usually cannot be restored by a single facility but rather require independent solutions. Exceptions may apply to certain types, e.g. fish lifts.

While significant knowledge and state-of-the-art measures are already available for restoring upstream migrations (Adam et al. 2005; BMLFUW 2012; Seifert 2012; DWA 2014), efficient solutions for downstream migrations are much less advanced and require further research and practical experience, especially in rivers with diverse fish assemblages (Böttcher et al. 2015).

Overall, while fish passes and bypass systems can reduce the impact of a barrier, they mostly cannot restore connectivity to pristine conditions as limitations might remain for selected species or life stages. Furthermore, barriers are usually related to other pressures, e.g. sedimentation processes in the impoundment with subsequent sediment deficit downstream (see Chap. 8), limited flow velocity in impoundments (see Chap. 6) or insufficient residual flow (see Chap. 4). These pressures, along with poorly executed fish passes, may contribute to migration delays, especially if spawning grounds are separated by several consecutive barriers.

Facilities for up- and downstream migration have to function as an alternative migration corridor. To be accepted as such, their design has to meet the requirements of migratory species (e.g. swimming capabilities, orientation, migration corridors). Therefore, knowledge of the following parameters is essential for the implementation of functional facilities:

1. An important factor for describing migratory capabilities of fish is the swimming speed, which is directly related to body length (i.e. expressed in body lengths per second; DVWK 1996) and depends on species- and age-specific characteristics (e.g. body shape, muscular system) as well as external factors (e.g. water temperature; DWA 2014). The respective pace also depends on the duration it can be sustained. However, in general, the "critical burst swimming speed" (i.e. speed at which drift occurs after $20 \mathrm{~s}$; Clough and Turnpenny 2001) of the weakest swimmer should serve as a benchmark for ecohydraulic planning of fish migration aids (Clough et al. 2004).

2. Although fish use all their senses for orientation, one main parameter is flow (Lucas and Baras 2001). As long as the flow velocity in the fish pass exceeds a species- and age-specific threshold (i.e. from 0.15 to $>0.30 \mathrm{~m} / \mathrm{s}$ ), fish show a positive rheoactive orientation (DWA 2014). 
3. Fish usually migrate within the main current or, in the case of too high flow velocities, parallel to it. Furthermore, the migration corridor (i.e. surface vs. bottom-oriented and shoreline vs. open water) depends on species-specific preferences (Seifert 2012). Bypasses have to be directly connected to migration corridors of all relevant species, and attraction flows should enhance their traceability.

\section{Facilities for Upstream Migration}

Several guidance documents on planning, construction and operation of fish passes were already developed or are currently under development (Dumont et al. 2005; BMLFUW 2012; Seifert 2012; Schmutz and Mielach 2013, 2015; DWA 2014).

As upstream migrations mostly serve reproduction, facilities have to support at least sexually mature age classes. Three main aspects have to be considered: (1) the perceptibility of the entry, (2) the passability of the fish pass and (3) post-passage effects.

Perceptibility depends to a high degree on the position and attraction flow of the fish pass entry. In general, it should directly link the fish pass to the natural migration corridor of fish and therefore be located close to the barrier, the main current (for hydropower plants, this means close to the turbines) and the shoreline. For oblique weirs, the pointed angle of the weir proved to be advantageous. For bottom-dwelling fish, a continuous connection to the river bottom is required (e.g. by a ramp with rough substrate and a slope $<1: 2$ ). Success may depend on a combination of several factors: multiple entries or collection galleries to cover wide barriers $(>100 \mathrm{~m})$, varying water levels and several species with different migration corridors and/or swimming capabilities.

The attraction flow has to provide a continuous connection between the migration corridors up- and downstream of the barrier. It should be as parallel as possible to the main current (e.g. $<30^{\circ}$ ), cause no turbulences and provide a high impulse of flow (defined as the product of volume and flow velocity; Larinier 2002; Seifert 2012). While the flow velocity is limited by the species' swimming capabilities, the volume can be further increased. At least 1-5\% of the turbined flow are required as attraction flow (Larinier 2002; Dumont et al. 2005). In many cases, the operational discharge, which only serves the passability of the fish pass, is too low and has to be enhanced by additional flow introduced into the lowest part of the fish pass. In this case, the installation of attraction flow turbines can reduce energetic losses (Hassinger 2009a; Seifert 2012).

Passability of a fish pass is ensured, if it provides a suitable migration corridor for all relevant species. This is the case when (a) hydraulic conditions do not exceed swimming capabilities, (b) the minimum rheoactive flow velocity is provided, (c) the spatial dimensions and geometry (depth, width and length) allow adult fish of the size-decisive species (i.e. species with highest spatial demands) to pass the entire fish pass and (d) continuous rough substrate supports bottom-dwelling and weaker species by ensuring moderate flow velocities towards the bottom.

With regard to post-passage effects, fish should be able to continue their migration (without the risk of downstream drift) and find suitable habitats. As 
unidirectional connectivity restoration can transform reservoirs into ecological traps (Pelicice and Agostinho 2008), upstream migration facilities have to be combined with downstream solutions (see below).

The selection of measures for upstream continuity restoration depends on the type of the barrier (e.g. function and use), local conditions (e.g. topology, space availability, fish assemblage) and financial resources and includes the following options:

1. The removal of barriers that no longer fulfil their purpose or have lost their functionality should be considered as a sustainable solution that also restores downstream connectivity. However, it requires prior assessment of related consequences (e.g. possible adverse effects on other facilities).

2. Rock ramps and river bottom sills may cover the entire riverbed or only parts of it (e.g. partial ramps). They are usually not hydropower-related but rather used for restoring barriers serving the purpose of flood control. They have the advantage of good perceptibility, provision of several migration corridors (also downstream), low sensitivity to debris (i.e. low maintenance costs) and habitat enrichment for rheophilic species (Gebler 2007). However, the disadvantages of very high construction costs and potentially reduced passability during low flows have to be considered (BMLFUW 2012).

3. Nature-like fish passes became popular in the 1980s in Central Europe and are now successfully built worldwide (Gough et al. 2012). Since nature-like bypass channels or pool-type fish passes mimic a small natural river, they do not only restore connectivity but also provide suitable habitats for reproduction and juvenile age classes. Thus, they can partially substitute the loss of fluvial habitats and can contribute to large-scale restoration if, e.g. installed as bypass system for chains of impoundments (see Chap. 6). One main disadvantage is, however, the high spatial demand and related high costs, especially if land acquisition is necessary.

4. Technical fish passes are usually built in a way that the slope is reduced over defined, constant height differences between pools, which are connected by slots or sluices. A multispecies-efficient representative of this type is the vertical-slot fish pass, but also other types (e.g. technical pool and weir fish pass, Denil fish pass or bristles pass) exist. Although this type does not provide suitable habitat for fish, is often more expensive in construction and requires increased maintenance, its low spatial demands and wide area of application represent major advantages (BMLFUW 2012).

5. The last group includes special constructions, which might only be used under certain conditions or in combination with other measures. As shipping locks show characteristics (i.e. low flow velocity, outside of migration corridor, no continuous attraction flow and functionality) that causes more random than targeted passage of fish, their application is not recommended as alternative passage for particular species (Travade and Larinier 2002; DWA 2014). Fish lifts guide fish into a chamber that is then moved upstream. Under certain circumstances, also trap-and-truck solutions might be feasible. However, all the above-described 
solutions have the disadvantage of discontinuous functionality, which is why their application has to be tested on a case-by-case basis.

In general, it can be concluded that upstream fish pass solutions are well developed and, in many cases, proven to successfully restore connectivity-at least for barriers of moderate height in small- to medium-sized rivers of temperate zones. However, there are currently no functional examples for large dams in tropical rivers where vast and diverse species assemblages and seasonal biomass peaks require special solutions (Schmutz and Mielach 2012).

\section{Facilities for Downstream Migration}

While measures for continuity restoration started with the construction of upstream fish passes, downstream migration problems were only recognized and addressed more recently (Larinier and Travade 2002). Therefore, solutions are less advanced and require further research and practical experience before they can be considered as state of the art (Böttcher et al. 2015). In any case, facilities supporting both up- and downstream migrations are required for restoring and maintaining healthy fish populations.

In contrast to upstream migrations, hydropower plants usually do not totally block downstream migrations, as fish still may be able to pass through turbines or opened spillways. However, depending on the local characteristics, fish entering these paths might get injured or even killed. Therefore, measures preventing fish from entering harmful plant components and providing alternative migration corridor are required. At the same time, progress continues in developing less harmful turbines that, however, still might not deserve to be called "fish-friendly".

Current measures for restoring connectivity in downstream direction include facilities for (1) improving safe passage, (2) prohibiting transit through harmful hydropower plant components and (3) providing alternative migration routes.

Based on thorough research of the parameters related to turbine injuries (Cada 2001; Larinier and Travade 2002), recommendations for mitigation include: reduce blade numbers, decrease the gap between the blade and its coating and lower the rotation velocity and pressure differences. Furthermore, new turbine concepts were developed. The VLH (very low head; www.vlh-turbine.com) turbine is applicable for heads of 1.4-3.2 $\mathrm{m}$ and flows of $10-26 \mathrm{~m}^{3} / \mathrm{s}$. While eels and salmon smolts showed promising survival rates $(92.3 \%)$, results on other species are still missing. Furthermore, both the Archimedean screw (Schmalz 2010) and the Alden turbine (i.e. applicable for heads from 20 to $30 \mathrm{~m}$ and flows $>30 \mathrm{~m}^{3} / \mathrm{s}$; Cook et al. 2003) promise high survival rates, whereby the latter has yet to be validated in the field. Another innovative example is the double rotating hydroconnect turbine, which is a gap-free screw with integrated fish lift. It was successfully tested in the rivers Jeßnitz (drop height, $3.3 \mathrm{~m}$; flow, $1 \mathrm{~m}^{3} / \mathrm{s}$ ) and Sulm (drop height, $5.5 \mathrm{~m}$; flow, $0.4 \mathrm{~m}^{3} / \mathrm{s}$ ) and allowed injury-free passage of many species and size classes (www.hydroconnect.at). Although its applicability for higher heads and flows still has to be assessed, it has the major advantage of being passable both ways.

If turbines cannot provide a safe passage, turbine entrainment has to be prohibited by physical barriers (e.g. rakes) sufficiently tight to provide effective protection also 
for small individuals. However, smaller clearances are usually connected with higher energetic losses (DWA 2014). Therefore, also in this field, efforts are made to develop physical barriers with low injury and passage rates as well as low hydraulic losses. Examples are the wedge wire screen and the Opperman screen (Hassinger 2009b). In general, the velocity in front of the screen should not exceed the critical swimming speed $(0.25-0.5 \mathrm{~m} / \mathrm{s})$. Although many studies investigate the functionality of behavioural barriers, which produce a repulsive stimulus (e.g. with electricity, air bubbles, light, sound), pilot experiments are not yet convincing especially for diverse species assemblages (Gosset and Travade 1999). While louvres and bar racks, which induce a certain flow pattern to guide fish towards a bypass, might represent suitable solutions for small hydropower plants, additional tests are required to prove their efficiency.

When shielding fish from harmful passage routes, alternative migration corridors have to be offered, and fish have to be attracted to enter them. Fish passes for upstream migration usually do not work for downstream migration since fish use other corridors for up- and downstream migration. However, fish can be guided into an existing fish pass via a bypass, which has to fulfil certain criteria to allow a safe transfer. Also spillway passage can be targeted under certain conditions. Finally, also trap and truck is possible, if no other solutions are suitable.

Fish pass facilities should function the whole year, and the assessment of their functionality should include indirect (i.e. measurement of abiotic parameters, e.g. flow velocity) and direct assessments (i.e. monitoring of successful passage, mortality, injuries of fish) (Woschitz et al. 2003).

\section{References}

Adam B, Bosse R, Dumont U, Hadderingh R, Jörgensen L, Kalusa B, Lehmann G, Pischel R, Schwevers U (2005) Fischschutz- und Fischabstiegsanlagen - Bemessung, Gestaltung, Funktionskontrolle. Deutsche Vereinigung für Wasserwirtschaft, Abwasser und Abfall e.V, Hennef

Amoros C, Roux AL (1988) Interaction between water bodies within the floodplain of large rivers: function and development of connectivity. Münstersche Geographische Arbeiten 29:125-130

Amoros C, Roux AL, Reygrobellet JL, Bravard JP, Pautou G (1987) A method for applied ecological studies of fluvial hydrosystems. Regul Rivers: Res Manage 1:17-36

Antongiovanni M, Metzger JP (2005) Influence of matrix habitats on the occurrence of insectivorous bird species in Amazonian forest fragments. Biol Conserv 122:441-451

BMLFUW (2012) Leitfaden zum Bau von Fischaufstiegshilfen. Bundesministerium für Land- und Forstwirtschaft, Umwelt und Wasserwirtschaft, Wien

Bosshard P (2015) 30 things you didn't know about rivers. Available http://www.huffingtonpost. com/peter-bosshard/30-things-you-didntknow_b_7812408.html

Böttcher H, Unfer G, Zeiringer B, Schmutz S, Aufleger M (2015) Fischschutz und Fischabstieg Kenntnisstand und aktuelle Forschungsprojekte in Österreich. Osterreichische Wasser- und Abfallwirtschaft 67:299-306

Bowne DR, Bowers MA, Hines JE (2006) Connectivity in an agricultural landscape as reflected by interpond movements of a freshwater turtle. Conserv Biol 20:780-791 
Branco P, Segurado P, Santos JM, Ferreira MT (2014) Prioritizing barrier removal to improve functional connectivity of rivers. J Appl Ecol 51:1197-1206

Cada GF (2001) The development of advanced hydroelectric turbines to improve fish passage survival. Fisheries 26:14-23

Clough SC, Turnpenny WH (2001) Swimming speeds in fish: phase 1. Environment Agency, Bristol

Clough SC, Lee-Elliott IE, Turnpenny AWH, Holden SDJ, Hinks C (2004) Swimming speeds in fish: phase 2 literature review. Environment Agency, Bristol

Colgan P (1993) The motivational basis of fish behavior. In: Pitcher TJ (ed) The behaviour of teleost fishes. Chapman and Hall, London, pp 31-55

Cook TC, Hecker GE, Amaral SV, Stacy PS, Lin F, Taft EP (2003) Final report - pilot scale tests Alden/concepts NREC turbine

Cote D, Kehler DG, Bourne C, Wiersma YF (2009) A new measure of longitudinal connectivity for stream networks. Landsc Ecol 24:101-113

Dumont U, Anderer P, Schwevers U (2005) Handbuch Querbauwerke. Ministerium für Umwelt und Naturschutz. Landwirtschaft und Verbraucherschutz des Landes Nordrhein-Westfalen, Düsseldorf

DVWK (Deutscher Verband für Wasserwirtschaft und Kulturbau E.V.) (1996) Merkblatt 232/1996 - Fischaufstiegsanlagen - Bemessung, Gestaltung, Funktionskontrolle. Deutscher Verband für Wasserwirtschaft und Kulturbau e.V. (DVWK), Bonn

DWA (Deutsche Vereinigung für Wasserwirtschaft, Abwasser und Abfall e. V.) (2014) Merkblatt DWA-M 509 - Fischaufstiegsanlagen und fischpassierbare Bauwerke - Gestaltung, Bemessung, Qualitätssicherung. Deutsche Vereinigung für Wasserwirtschaft, Abwasser und Abfall e.V, Hennef

Dynesius M, Nilsson C (1994) Fragmentation and flow regulation of river systems in the nothern third of the world. Science 266:753-762

European Commission (1992) Council Directive 92/43/EEC of 21 May 1992 on the conservaiton of natural habitats and of wild fauna and flora

European Commission (2000) Directive 2000/60/EC of the European Parliament and the Council of 23 October 2000. Establishing a framework for community action in the field of water policy

Fagan WF (2002) Connectivity, fragmentation, and extinction risk in dendritic metapopulations. Ecology 83:3243-3249

Freyhof J, Brooks E (2011) European red list of freshwater fishes. Publication Office of the European Commission, Luxembourg

Fullerton AH, Burnett KM, Steel EA, Flitcroft RL, Pess GR, Feist BE, Torgersen CE, Miller DJ, Sanderson BL (2010) Hydrological connectivity for riverine fish: measurement challenges and research opportunities. Freshw Biol 55:2215-2237

Gebler J (2007) Rock ramps and nature-like-bypass-channels - design-criteria and experiences. IFAC Working Party - Fish passage best practices, Salzburg. Oct 8-10

Gosset C, Travade F (1999) Etudes de dispositifs d'aide à la migration de dévalaison des salmonidés: barrières comportementales? Cybium 23:45-66

Gough P, Philipsen P, Schollema PP, Wanningen H (2012) From sea to source - international guidance for the restoration of fish migration highways. Regional Water Authority Hunze en Aa's, Veendam

Grill G, Dallaire CO, Chouinard EF, Sindorf N, Lehner B (2014) Development of new indicators to evaluate river fragmentation and flow regulation at large scales: a case study for the Mekong river basin. Ecol Indic 45:148-159

Hartmann J, Harrison D, Opperman J, Gill R (2013) Planning at the system scale - the next frontier of hydropower sustainability. The Nature Conservancy, s.1

Hassinger R (2009a) Energieeffiziente künstliche Erzeugung von Leitströmungen bei Fischwanderhilfen. Österreichische Wasser und Abfallwirtschaft 3-4:32-34

Hassinger R (2009b) Neuartiger Fisch schonender Rechen für Wasserkraftanlagen. Desdener Wasserbauliche Mitteilungen Heft 39:251-258 
ICOLD (International Commission on Large Dams) (2016) Available http://www.icold-cigb.org/ GB/World_register/general_synthesis.asp

ICPDR (2013) Sustainable hydropower development in the Danube basin - guiding principles. ICPDR - International Commission for the Protection of the Danube River, Vienna

ICPDR (2015) Danube river basin district management plan - update 2015. ICPDR - International Commission for the Protection of the Danube River, Vienna

Jungwirth M (1998) River continuum and fish migration - going beyond the longitudinal river corridor in understanding ecological integrity. In: Jungwirth M, Schmutz S, Weiss S (eds) Fish migration and fish bypasses. Fishing News Books, Oxford, pp 19-32

Jungwirth M, Muhar S, Schmutz S (2000) Fundamentals of fish ecological integrity and their relation to the extended serial discontinuity concept. Hydrobiologia 422(423):85-97

Jungwirth M, Haidvogl G, Moog O, Muhar S, Schmutz S (2003) Angewandte Fischökologie and Fließgewässern. Facultas Universitätsverlag, Wien

Karle KF (2005) Analysis of an efficient fish barrier assessment protocol for highway culverts. Juneau. Final report to Alaska Department of Transportation. FHWA-AK-RD-05-02

Keitt TH, Urban DL, Milne BT (1997) Detecting critical scales in fragmented landscapes. Ecol Soc $1: 4$

Kemp PS, O'Hanley JR (2010) Procedures for evaluating and prioritising the removal of fish passage barriers: a synthesis. Fish Manag Ecol 17:297-322

Kuby MJ, Fagan WF, ReVelle CS, Graf WL (2005) A multiobjective optimization model for dam removal: an example trading off salmon passage with hydropower and water storage in the Willamette basin. Adv Water Resour 28:845-855

Labonne J, Ravigne V, Parisi B, Gaucherel C (2008) Linking dendritic network structures to population demogenetics: the downside of connectivity. Oikos 117:1479-1490

Lancaster J (2000) Geometric scaling of microhabitat patches and their efficacy as refugia during disturbance. J Anim Ecol 69:442-457

Larinier M (2002) Fishways - general considerations. Bulletin Français de la Pêche et de la Pisciculture 364(Suppl):23-38

Larinier M, Travade F (2002) Downstream migration: problems and facilities. Bulletin Français de la Pêche et de la Pisciculture 364(Suppl):181-207

Latham J, Collen B, McRae L, Loh J (2008) The living planet index for migratory species: an index of change in population abundance. Final Report for the Convention on the Conservation of Migratory Species, London

Lucas MC, Baras E (2001) Migration of freshwater fishes. Blackwell Science, Oxford

Mader H, Unfer G, Schmutz S (1998) The effectiveness of nature-like bypass channels in a Lowland river, the Marchfeldkanal. In: Jungwirth M, Schmutz S, Weiss S (eds) Fish migration and fish bypasses. Fishing News Books, Oxford, pp 384-402

Master L (1990) The imperiled status of North American aquatic animals. Biodivers Netw News 3:1-8

Mesa MG, Magie CD (2009) Prioritizing removal of dams for passage of diadromous fishes on a major river system. River Res Appl 25:107-117

Moilanen A, Hanski I (2006) Connectivity and metapopulation dynamics in highly fragmented landscapes. In: Crooks KR (ed) Connectivity conservation. Cambridge University Press, Cambridge, pp 44-71

Nilsson C, Reidy CA, Dynesius M, Revenga C (2005) Fragmentation and flow regulation of the world' s large river systems. Science 308:405-408

Northcote TG (1978) Migratory strategies and produciton in freshwater fishes. In: Gerking SD (ed) Ecology of freshwater fish production. Blackwell Publishing Ltd, Oxford, pp 326-359

Northcote TG (1998) Migratory behavior of fish and its significance to movement through riverine fish passagee facilities. In: Jungwirth M, Schmutz S, Weiss S (eds) Fish migration and fish bypasses. Fishing News Books, Oxford, pp 3-18

O'Hanley JR (2011) Open rivers: barrier removal planning and the restoration of free-flowing rivers. J Environ Manag 92:3112-3120 
O'Hanley JR, Tomberlin D (2005) Optimizing the removal of small fish passage barriers. Environ Model Assess 10:85-98

Opperman J, Grill G, Hartmann J (2015) The power of rivers: finding balance between energy and conservation in hydropower development. The Nature Conservancy, Washington, DC

Ovidio BM, Philippart JC (2008) Movement patterns and spawning activity of individual nase Chondrostoma nasus (L.) in flow-regulated and weir-fragmented rivers. J Appl Ichthyol 24:256-262

Pavlov DS (1989) Structures assisting the migrations of non-salmonid fish: USSR. Food and Agriculture Organization of the United Nations, Rome

Pelicice FM, Agostinho AA (2008) Fish-passage facilities as ecological traps in large neotropical rivers. Conserv Biol 22:180-188

Pringle C (2006) Hydrologic connectivity: a neglected dimension of conservation biology. In: Crooks KR (ed) Connectivity conservation. Cambridge University Press, Cambridge, pp 233-254

Pringle CM, Freeman MC, Freeman BJ (2000) Regional effects of hydrologic alterations on riverine macrobiota in the new world: tropical-temperate comparisons. Bioscience 50:807-823

Rosenberg DM, Mccully P, Pringle CM (2000) Global-scale environmental effects of hydrological alterations: introduction. Bioscience 50:746-752

Schmalz W (2010) Untersuchungen zum Fischabstieg und Kontrolle möglicher Fischschäden durch die Wasserkraftschnecke an der Wasserkraftanlage Walkmühle an der Werra in Meiningen Abschlussbericht. Im Auftrag der Thüringer Landesanstalt für Umwelt und Geologie, Breitenbach

Schmutz S, Mielach C (2012) Scoping of existing research on fish passage through large dams and its applicability to Mekong mainstream dams. Inception paper. 1-25

Schmutz S, Mielach C (2013) Measures for ensuring fish migration at transversal structures technical paper. International Commission for the Protection of the Danube River, Vienna

Schmutz S, Mielach C (2015) Review of existing research on fish passage through large dams and its applicability to Mekong mainstream dams. Mekong River Commission, Phnom Penh

Schmutz S, Zitek A, Dorninger C (1997) A new automatic drift sampler for riverine fish. Hydrobiol 139:449-460

Segurado P, Branco P, Ferreira MT (2013) Prioritizing restoration of structural connectivity in rivers: a graph based approach. Landsc Ecol 28:1231-1238

Seifert K (2012) Praxishandbuch: Fischaufstiegsanlagen in Bayern. Hinweise und Empfehlungen zu Planung, Bau und Betrieb. Bayerisches Landesamt für Umwelt, München

Seliger C, Scheikl S, Schmutz S, Schinegger R, Fleck S, Neubarth J, Walder C, Muhar S (2016) HY:CON: a strategic tool for balancing hydropower development and conservation needs. River Res Appl 32:1438-1449

Spindler T, Chovanec A, Zauner G, Mikschi E, Kummer H, Wais A, Spolwind R (1997) Fischfauna in Österreich: Ökologie-Gefährdung-Bioindikation-Fischerei-Gesetzgebung. Umweltbundesamt, Wien

Tischendorf L, Fahrig L (2000) How should we measure landscape connectivity? Landsc Ecol 15:633-641

Travade F, Larinier M (2002) Fish locks and fish lifts. Bulletin Français de la Pêche et de la Pisciculture 364:102-118

Vannote RL, Minshall GW, Cummins K, Sedell JR, Cushing CE (1980) The river continuum concept. Can J Fish Aquat Sci 37:130-137

Vörösmarty CJ, McIntyre PB, Gessner MO, Dudgeon D, Prusevich A, Green P, Glidden S, Bunn SE, Sullivan CA, Liermann CR, Davies PM (2010) Global threats to human water security and river biodiversity. Nature 467:555-561

Waidbacher H, Haidvogl G (1998) Fish migration and fish passage facilities in the Danube: past and present. In: Jungwirth M, Schmutz S, Weiss S (eds) Fish migration and fish bypasses. Fishing News Books, Oxford, pp 85-98

Ward JV (1989) The four-dimensional nature of lotic ecosystems. J N Am Benthol Soc 8:2-8 
Ward JV (1997) An expansive perspective of riverine landscapes: pattern and process across scales. River Ecosyst 6:52-60

Ward JV, Stanford JA (1983) The serial discontinuity concept of lotic ecosystems. In: Fontaine TD, Bartell SM (eds) Dynamics of lotic ecosystems. Ann Arbor Science, Michigan, pp 29-42

Ward JV, Stanford JA (1995a) Ecological connectivity in alluvial river ecosystems and its disruption by flow regulation. Regul Rivers Res Manag 11:105-119

Ward JV, Stanford JA (1995b) The serial discontinuity concept: Extending the model to floodplain rivers. Regul Rivers Res Manag 10:159-168

Wiens JA (2002) Riverine landscapes: taking landscape ecology into the water. Freshw Biol 47:501-515

Woschitz G, Eberstaller J, Schmutz S (2003) Mindestanforderungen bei der Überprüfung von Fischmigrationshilfen (FMH) und Bewertung der Funktionsfähgikeit. Österreichischer Fischereiverband, Wien

WWF (2006) Free-flowing rivers: economic luxury or ecological necessity? World Wildlife Fund, Zeist

Open Access This chapter is licensed under the terms of the Creative Commons Attribution 4.0 International License (http://creativecommons.org/licenses/by/4.0/), which permits use, sharing, adaptation, distribution and reproduction in any medium or format, as long as you give appropriate credit to the original author(s) and the source, provide a link to the Creative Commons license and indicate if changes were made.

The images or other third party material in this chapter are included in the chapter's Creative Commons license, unless indicated otherwise in a credit line to the material. If material is not included in the chapter's Creative Commons license and your intended use is not permitted by statutory regulation or exceeds the permitted use, you will need to obtain permission directly from the copyright holder. 